\title{
A FUNÇÃO SOCIAL DO PROFESSOR: ASPECTOS HISTÓRICOS*
}

Maria Elisabeth Blanck Miguel **

No Brasil, historicamente o professor aparece como alguém a serviço do governo e mais tarde, quando se organiza o Estado $^{\mathbf{1}}$ brasileiro (após a Independência) como seu funcionário.

No entanto, é a partir deste século quando nasce a industrialização no Brasil e modificam-se as relações de produção, que a escola (e conseqüentemente o trabalho do professor) passa a ser sentida pela população como instituição social necessária. Por que seriam tão necessários a escola e o trabalho do professor? Porque o professor transmitia as técnicas de domínio da leitura e da escrita e ainda mais, os conhecimentos necessários para que os alunos ingressassem no trabalho industrial e comercial. Isto era percebido pela população como possibilidade de participar da produção e do comércio concorrendo a melhores salários e tendo acesso a melhores formas de vida social.

"Em 1921, duplicaram as matrículas escolares em relação a cinco anos antes, isto é, de pouco mais de 16.000 alunos matriculados em 1916, 30.800 matricularam-se em 1921" (Miguel, 1997, p.24). Ainda no mesmo ano, o inspetor Prieto Martinez, relatava que, dos "13.000 alunos matriculados analfabetos, mais de 8000 aprenderam a ler, escrever e contar (...) muitos desses, satisfeitos com o que aprenderam, deixaram os bancos escolares para entrar definitivamente na vida prática (Paraná, Relatório, 1921, p.13).

A escola e a institucionalização do trabalho do professor foram se efetivando, não tanto pelo esforço do governo, mas "conquistada pela população", de tal forma que no Paraná, nas primeiras décadas do século "já se

* Trabalho apresentado no III Congresso Luso-brasileiro - Coimbra - 23 a 26 de fevereiro de 2000
** Prof. ${ }^{\text {a }}$ Dr. ${ }^{\text {a }}$ do corpo docente do Curso de Mestrado em Educação, PUCPR. 
constatavam em alguns centros urbanos escolas superlotadas pelos alunos e inúmeros abaixo-assinados de pais que pediam professores para seus filhos" (WACHOWICZ, 1984, P.6).

Qual o significado desses fatos? Certamente significava que a população via no trabalho do professor uma função social: a função de servir de mediação para a participação do indivíduo na sociedade que se complexificava. Há que se chamar atenção para o fato de que o Paraná não se industrializou na primeira metade deste século, mas sofreu o impacto da industrialização paulista, enquanto produzia matérias-primas para as indústrias (sobretudo, o café). O Paraná só se industrializa em 1960 quando a COPEL (Companhia Paranaense de Energia Elétrica) estende a rede elétrica por todo o estado, criando assim condições para a instalação de indústrias maiores.

Mas, a importância da escola e do trabalho do professor, foram percebidos no início do século, também por influência da presença de estrangeiros no Paraná. Nas colônias de imigrantes, a escola tinha função social mais claramente definida. Acostumados em seus países a providenciar escola por sua própria iniciativa, também o fizeram no Brasil, acrescentando a este motivo: a possibilidade de transmitir às gerações mais novas, os valores culturais da pátria de origem, inaugurarando um tipo de escola que poderia ser chamado de comunitário (WACHOWICZ, 1984, p.208).

Nessas escolas o professor era escolhido pela comunidade e pago por ela; tinha a função de manter vivos os valores da cultura de origem.

Nas escolas brasileiras, sempre carentes de cuidados e de material, os professores mal pagos as mantinham às suas próprias custas, pois elas funcionavam em uma das salas de suas próprias casas. Embora nos discursos oficiais a educação fosse apontada como prioridade, não o era na distribuição das verbas. Há que se distinguir então (e ainda hoje), entre a função social da escola e do trabalho do professor proclamada nos discursos oficiais e a função social reconhecida e demandada pela população.

Nos discursos oficiais, a educação escolar e o trabalho do professor ainda agora são proclamados como prioridades mas não são assim contemplados na distribuição de verbas e na garantia das condições estruturais para 0 trabalho educacional. Tal fato significa que a verdadeira função social da escola e do professor: a de transmitir as técnicas elementares de acesso ao código escrito, os conhecimentos científicos fundamentais e os valores e atitudes básicos para a formação da cidadania não encontram por parte daqueles que deveriam garantí-los, as condições mínimas que assegurem a sua transmissão para todos. Ou seja, historicamente por parte dos governantes, a real função social do professor tem sido obstaculizada, quer nas condições de trabalho, quer na sua formação, quer no reconhecimento social sob a forma de salário, plano de carreira, etc... 
Para exemplificar: em 1928, na reforma que instituiu a Escola Normal como curso separado do antigo ginásio, transferindo-a para o prédio do Palácio da Instrução (Instituto de Educação do Paraná) dando-lhe um currículo próprio, seu reformador Lysímaco Ferreira da Costa, dizia que o Estado deveria cuidar da educação do povo. Esta era definida como a tarefa de criar nele o "hábito do trabalho produtor" (COSTA, 1987, p.129).

A expressão "trabalho produtor" significava:

Despertar no menino o espírito de iniciativa individual; despertar nele a capacidade necessária para transformar suas idéias em atos racionalmente executados, em resumo, ensinar a pensar e agir é o objetivo capital do trabalho manual que, introduzido lentamente nas Escolas Primárias, seja pelo Estado, seja pelos municípios ou pela iniciativa particular, se torna o único meio de verdadeiro combate ao analfabetismo, e o único meio de transformar, pela boa escola, a nossa indolência em sã atividade produtora. (COSTA, 1987, P.129).

(Os grifos são nossos).

No discurso oficial ficava explícita a função social da escola e por extensão, do trabalho do professor: formar o homem produtor através de um mínimo de conhecimentos e do trabalho manual. 0 trabalho manual não entrava no discurso e no currículo, por acaso. É que o trabalho manual imprimia ao desenvolvimento da atividade, a obediência e a disciplina, qualidades necessárias, no entendimento das autoridades, para afastar a preguiça congênita do povo, transformando-o no trabalhador produtivo, obediente e disciplinado.

Tais argumentos ficavam mais claros na seqüência dos escritos de Ferreira da Costa, quando reafirmava o aforisma "a escola é o professor " e completava:

fazer o bom professor é função capital do Estado; disseminar o maior número possível de escolas, na medida das suas forças orçamentárias, é o problema conseqüente. Mas sempre devemos preferir poucas e boas escolas, porque nada há de mais funesto, para a educação de um povo, que a má escola. (COSTA, 1987, P.129)

A função social do trabalho do professor ficava mais explícita quando se tratava de escolher os que iriam lecionar na Escola Normal. A escolha deveria recair sobre aqueles considerados segundo a retidão de caráter, embora o professor pudesse ter pouco "relevo intelectual no seio de sua classe" (COSTA, 1987, P.132). A pouca capacidade intelectual tornava-se questão secundária, desde que o mestre fosse obediente ao Estado e ajudasse a formar também, cidadãos obedientes. 
As palavras de Lysímaco não eram apenas manifestação da sua forma individual de ver a questão da educação pública e do trabalho do professor, mas na verdade representavam o pensamento da elite governante nacional.

Reportamo-nos aos exemplos retirados da história da educação paranaense porque eles nos ajudam a destacar que a função social do trabalho do professor apontada pelo Estado, não tem correspondido à função social da escola e do professor percebida pela população.

Esta diferença de percepção é resultante de vários fatores, entre os quais se incluem a falta de escolarização do povo e o fato de que, no equilíbrio de forças das classes sociais do Estado, as elites tem tido historicamente, maior representação. Enquanto classe dirigente percebem a função social da escola como um dos modos de preparar o cidadão produtor e obediente. Só quando a classe trabalhadora se organiza, exerce pressão, reivindica ou consegue uma representação política que sustente seus interesses, é que ela obtém ganhos sociais. Ou quando as demandas do próprio sistema de produção capitalista cria tais necessidades.

O modo como desenvolveram-se as relações sociais de produção no Brasil, marcaram profundamente as diferenças entre as classes sociais. Nesse contexto, desenvolveram-se em nível nacional e também no Paraná, a política educacional de formação de líderes nos cursos universitários e nos cursos de magistério. Os melhores alunos dos cursos eram preparados como líderes: os dos cursos universitários iriam ocupar cargos administrativos no Estado; os do magistério moldariam a alma popular. $\mathrm{O}$ trabalho de moldagem da alma nacional repousava sobre a alfabetização e transmissão de conhecimentos básicos, a higiene e a moral. Preparar líderes nos cursos de magistério significava que a função social do trabalho do professor era a de formar o homem produtivo, isto é, com algum conhecimento, saudável e moralmente obediente. Essa questão tinha a ver com a questão maior da organização do trabalho nacional. Os professores contribuíam para esta organização nas cidades e nas zonas rurais. Nas cidades, preparando o homem para trabalhar na fábrica e no comércio (bancos, etc.) enquanto pessoas alfabetizadas, dominando conhecimentos básicos das ciências, da história e da geografia e ainda com hábitos higiênicos e obedientes. No campo, preparando o trabalhador para aí permanecer. Justificava-se assim, a presença da Agronomia como uma das disciplinas dos currículos de formação dos professores, por um bom tempo. É importante salientar que os habitantes das zonas rurais deveriam receber os mesmos conhecimentos dos das zonas urbanas, acrescentando-se aqueles necessários para a vida do campo.

Essa função social do trabalho do professor se estende até a década de 60 quando a crise entre o modelo político tendendo ao nacional desenvolvimentismo e o modelo econômico de desenvolvimento associado ao capital internacional, se confrontam. Há, então, o movimento de 1964 que 
opta pelo modelo de desenvolvimento associado. Muitas modificações advém desse fato e a educação não fica fora dela. O professor passa a ser visto como aquele que vai executar os objetivos emanados do sistema. Na verdade, continua prevalecendo a ótica do Estado de que o professor vai moldar o povo para trabalhar mais e melhor, em menos tempo, colaborando para os objetivos considerados importantes para o desenvolvimento nacional.

No período posterior ao movimento de 1964 o enfoque da educação do homem para o trabalho é maximizada. Saem dos currículos as disciplinas que levam à reflexão, como a Filosofia e entram atividades como Sondagem de Aptidões dos alunos e Iniciação para o Trabalho, já no $1^{10}$ grau. Os cursos de $2^{\underline{o}}$ grau são vistos como formadores de técnicos.

Com a abertura política no início dos anos 80, discute-se o papel reprodutivista que a escola desenvolve e é negada a sua função social. Conseqüentemente é negada também a função social do professor como formador de novas gerações.

É nesse contexto que Saviani, fundamentado em Gramsci, recupera teoricamente a função social da escola: a de transmissora de conhecimentos. Este resgate da função da escola e do professor se insere num período da história brasileira, no qual muitos pregavam a desescolarização, e atribuíam tais funções para outras instituições. A reafirmação de Saviani, de que a função específica da escola era transmitir conhecimentos, acabou sendo entendida como limitadora da sua função social. Mas, naquele momento era necessário tal assertiva, pois a especificidade educativa escolar havia se perdido em meio às outras atividades secundárias. Aceita a reafirmação da função específica da escola e do professor, podemos repensá-la considerando o contexto atual no qual vivemos. Qual é a nossa função social no atual contexto? O que podemos fazer na escola e fora dela?

Acreditamos que temos que aceitar o pressuposto de que a função primordial da escola é transmitir os conhecimentos. Mas, de que conhecimentos estamos falando? Estamos falando dos conhecimentos científicos básicos e daqueles que explicam ou ajudam a entender a realidade.

Para exemplificar como trabalhar na escola ensinando os alunos a compreenderem a realidade, lembramos de um trecho publicado em Diário Oficial do Estado do Paraná, sobre os programas dos antigos Cursos Normais Regionais e que, no nosso entendimento ainda não alcançamos. Dizia ele que a cadeira de matemática deveria ser fundamentalmente a oportunidade para "uma ampla reflexão sobre o ambiente, sobretudo econômico do município" (PARANÁ. Decreto 8.862/49, p.3) e quiçá do Estado e da União.

A importância do conhecimento aritmético, da idéia de medida, na vida diária, a partir do levantamento das ocasiões nas quais as mesmas aparecem em situações de sala de aula, era sugerida como ponto inicial da relação que o professor, necessariamente, deveria fazer entre a Aritmética e a vida. 
Este exercício estender-se-ia para situações fora da classe e relações mais extensas iriam estabelecelendo-se.

Sugeria-se que, de posse do orçamento da Prefeitura, os alunos refletissem sobre a aplicação do dinheiro público e a conveniência ou não da aplicação de certas parcelas. Do orçamento do município passar-se-ia para 0 do Estado e o da União.

Ensinar os alunos a compreender a realidade através dos conhecimentos que ele aprende na escola e formar sua consciência crítica e sua cidadania é hoje a função social do professor. Mas, para isso ele precisa necessariamente, estar atualizado nos conhecimentos da sua área de ensino e, em permanente contato com os fatos que o cercam. Precisa também atuar junto com seus pares, na organização da sua categoria, procurando dessa forma, garantir as condições que assegurem a realização da sua função na sociedade: a de formar cidadãos. A escola não realizará sua função social sozinha; necessitará da interação com outras instituições assim como de uma legislação orgânica que a ampare.

Os objetivos pensados para a formação do professor que iria atuar nas escolas regionais é, ainda hoje, ponto de partida para projetarmos as demais metas necessárias à chamada "sociedade do conhecimento", na qual os meios de comunicação são extremamente rápidos e de características bem diversas daquelas de então.

Nesta "nova sociedade do conhecimento", o homem está inserido numa determinada forma de organização social que pressupõe que ele venha ser um trabalhador flexível, sempre pronto a desenvolver diferentes atividades: o importante seria que a educação formal lhe desse uma base de conhecimentos e desenvolvesse-lhe habilidades para a diversidade do trabalho.

Mas, mesmo aceitando que as solicitações do mercado globalizado, altamente competitivo e excludente exigem o homem preparado para nele atuar, acreditamos que fundamentalmente a função social da escola e do professor seja o compromisso com a formação do cidadão. Esta formação precisa ter como horizonte, necessariamente, a cidadania, que se inicia quando os alunos se tornam partícipes dos conhecimentos socialmente produzidos. No ato de assimilar, aprender tais conhecimentos, os alunos desenvolvem valores humanos. Para tanto é necessário que seja dado ao ato de aprender a dimensão social.

Em qualquer nível de escolaridade, a história da educação nos mostra que foram positivamente significativos os conhecimentos legitimados pelos valores humanos, ou seja, enquanto passíveis de aplicação em prol da humanidade. Marcovitch, em artigo publicado no jornal "Folha de São Paulo" (9/3/99) ao discutir os valores universitários afirma que estes "devem ser construídos coletivamente em Academia" e completa: 
"O empobrecimento da vida cívica na moderna sociedade de consumo, tão lamentado pelos críticos da cultura liberal assume proporções ainda mais perigosas nos países jovens, como o Brasil. Aqui, a escassez de oportunidades cria perigoso espaço para a ambição desmedida, a inveja, a disputa feroz, a falta de coesão social. A universidade nesse contexto selvagem, tem um enorme papel corretivo e civilizador a exercer. $\mathrm{O}$ culto aos valores humanos é o caminho certo para desempenhá-lo".

(Folha de São Paulo,09/03/99 / cad.1, p.03)

Neste artigo estamos considerando a educação formal enquanto um processo que se estende da educação infantil à educação superior e queremos reafirmar que o desenvolvimento dos valores humanos se faz a partir da assimilação e produção dos conhecimentos, pela função social que os mesmos possam ter. Tal função é de natureza da ação educativa; é função social da escola e do professor. Somente a partir de bases sólidas de conhecimentos fundamentados em valores humanistas, o aluno será um cidadão comprometido com a melhoria do homem e do mundo.

\section{Nota}

1 Estamos considerando o conceito de Estado segundo Ianni, para quem "o Estado resulta das relações de classes sociais" e como "mediação nas relações entre classes hierarquizadas, ele ganha vinculações mais ou menos estreitas com a classe dominante", constituindo-se "nessas relações como órgão da classe dirigente. Porém o Estado nunca perde o seu caráter de produto das relações de classes antagônicas. Por isso, não pode ser reduzido à condição de instrumento puro e simples da classe dominante". (IANNI, 1988, P.117).

\section{Referências bibliográficas}

COSTA, Maria José Franco Ferreira da. Lysímaco Ferreira da Costa (a dimensão de um homem) Curitiba: UFPR, 1987.

IANNI, Octávio. Estado e capitalismo. São Paulo: Brasiliense, 1989.

MARCOVITCH, Jacques. Valores universitários, In: Tendências e debates. Folha de São Paulo, São Paulo, 9/3/1999, cad. 1, p.3.

MGUEL, Maria Elisabeth Blanck. A formação social do professor e a organização social do trabalho. Curitiba, Ed. da UFPR, 1997.

PARANÁ. Decreto n.o 8.862 de 17 de nov. de 1949. Aprova os programas dos Cursos Normais Regionais. Diário Oficial de 24 jan. 1950. 
PARANÁ. Relatório apresentado ao Secretário Geral de Estado pelo Professor César Pietro Martinez, Inspetor Geral de Ensino, 1921, Curitiba: Tip. da Penitenciária do Estado.

WACHOWICZ, Lilian Anna. Relação professor-estado no Paraná tradicional. São Paulo: Cortez, 1984. 